International Journal of Child, Youth and Family Studies (2014) 5(1): 89-112

\title{
SCHOOL-BASED STRATEGIES TO REDUCE SUICIDAL IDEATION, SUICIDE ATTEMPTS, AND DISCRIMINATION AMONG SEXUAL MINORITY AND HETEROSEXUAL ADOLESCENTS IN WESTERN CANADA
}

\author{
Elizabeth M. Saewyc, Chiaki Konishi, Hilary A. Rose, and Yuko Homma
}

\begin{abstract}
This study explored the relationships between the existence of and length of time since implementation of school-based Gay-Straight Alliances (GSAs) and explicit antihomophobic bullying policies in secondary schools across British Columbia, Canada, with experiences of anti-gay discrimination, suicidal ideation and attempts among lesbian, gay, bisexual (LGB), mostly heterosexual, and exclusively heterosexual students. Analyses of the province-wide random cluster-stratified 2008 B.C. Adolescent Health Survey $(n=21,708)$ compared students in schools with GSAs or policies implemented at least 3 years, and less than 3 years, with those in schools without GSAs or anti-homophobia policies, using multinomial logistic regression, separately by gender. LGB students had lower odds of past year discrimination, suicidal thoughts and attempts, mostly when policies and GSAs had been in place for 3+ years; policies had a less consistent effect than GSAs. Heterosexual boys, but not girls, also had lower odds of suicidal ideation and attempts in schools with longer-established antihomophobic bullying policies and GSAs. Given consistently higher documented risk for suicidal ideation and attempts among LGB and mostly heterosexual adolescents, prevention efforts should be a priority, and school-level interventions, such as GSAs, may be an effective approach to reducing this risk, while also offering prevention benefits for heterosexual boys.
\end{abstract}

Keywords: sexual orientation, suicidal ideation, suicide attempt, gay-straight alliance, adolescent, school policy, school-based surveys, homophobia

Acknowledgments: These analyses were supported in part by grants \#CPP-86374 and \#MOP119472 from the Canadian Institutes of Health Research, Institute of Population and Public Health, and Institute of Gender and Health (Saewyc, PI). The authors acknowledge the McCreary Centre Society, Vancouver, for permission to access the 2008 B.C. Adolescent Health Survey.

Elizabeth Saewyc, Ph.D, RN, FSAHM, FCAHS (the corresponding author) is Professor of Nursing and Adolescent Medicine, and Director of the Stigma and Resilience Among Vulnerable Youth Centre, at the University of British Columbia School of Nursing, T201-2211 Wesbrook Mall, Vancouver, B.C., Canada, V6T 2B5. Office Telephone: (604) 822-7505. Fax: (604) 822-7466.

E-mail: elizabeth.saewyc@ubc.ca 
International Journal of Child, Youth and Family Studies (2014) 1: 89-112

Chiaki Konishi, Ph.D. is a postdoctoral fellow in the Stigma and Resilience Among Vulnerable Youth Centre, at the University of British Columbia School of Nursing, T201-2211 Wesbrook Mall, Vancouver, B.C., Canada, V6T 2B5. E-mail: chiaki.konishi@ubc.ca

Hilary Rose, Ph.D. is an Associate Professor of Child \& Family Development at Concordia University, 1455 de Maisonneuve Blvd. West, Montreal, Quebec, Canada, H3G 1M8.

E-mail: hilary.rose@concordia.ca

Yuko Homma, Ph.D. is a postdoctoral fellow in the Stigma and Resilience Among Vulnerable Youth Centre, at the University of British Columbia School of Nursing, T201-2211 Wesbrook Mall, Vancouver, B.C., Canada, V6T 2B5. E-mail: yuko.homma@ubc.ca

In spite of a significant increase in research about the mental health issues in sexual minority youth over the past couple of decades, there is little research about various protective factors that may mitigate the risks facing lesbian, gay, or bisexual (LGB) and "mostly heterosexual” youth, and potentially prevent mental health problems. Recent reviews have summarized the health disparities experienced by sexual minority youth compared to their exclusively heterosexual peers, including greater prevalence of harassment, victimization, depression, substance abuse, and suicidality (Coker, Austin, \& Schuster, 2010; King, Semlyn, Tai, et al., 2008; Saewyc, 2011). With respect to suicidality (suicidal thoughts and attempts) among sexual minority youth, recent large population-based studies and meta-analyses have been remarkably consistent on the topic (Haas et al., 2011; Marshal et al., 2011; Saewyc, Skay, et al., 2007): Sexual minority youth are more likely than their heterosexual peers to be suicidal, not only in North America, but also in countries such as New Zealand (Lucassen et al., 2011), Norway (Wichstrom \& Hegna, 2003), and Turkey (Eskin, Kaynak-Demir, \& Demir, 2005).

Suicidality in sexual minority youth is associated with individual mental health factors such as depression, as well as interpersonal or relational factors, including enacted stigma (discrimination, harassment, abuse, and other victimization). Researchers have documented a strong association between victimization of sexual minority youth and suicidality (Birkett, Espelage, \& Koenig, 2009; D’Augelli, Pilkington, \& Hershberger, 2002; Goodenow, Szalacha, \& Westheimer, 2006; Rivers, 2001).

Several authors have argued that health issues related to sexual orientation in adolescence must be viewed in the wider social context (Goodenow et al., 2006; Horn, Kosciw, \& Russell, 2009; Hatzenbuehler, 2011; Rose, 2009). To the extent that LGB and mostly heterosexual youth are more likely to experience the negative environments or exposures that have been implicated in suicide attempts generally, this may help explain their higher risk of suicidality (Saewyc, 2007). Others have also argued that researchers need to look beyond risk factors and consider protective factors that promote resilience in at-risk youth (Russell, 2005; Saewyc, 2011; Savin-Williams, 2005). Emerging evidence suggests that feeling safe at school and school connectedness or attachment are important protective factors for all youth that may also reduce the likelihood of depression, suicidal ideation, or suicide attempts in sexual minority youth (Eisenberg \& Resnick, 2006; Galliher, Rostosky, \& Hughes, 2004; Homma \& Saewyc, 2007). 
International Journal of Child, Youth and Family Studies (2014) 1: 89-112

Furthermore, sexual minority students are not alone in being the targets of anti-gay homophobia and bullying in the school context. Several authors have reported that heterosexual youth can also be targets of anti-gay bullying (Smyser \& Reis, 2002; Saewyc, Poon, et al., 2007; Swearer, Turner, Givens, \& Pollack, 2008; see also North Vancouver School District No. 44 v. Jubran, 2005). As a result, several authors have recommended policy changes with respect to improving school climate not only for sexual minority youth, but also for heterosexual youth (Kosciw, Greytak, Diaz, \& Bartkiewicz, 2010; Taylor et al., 2011). Other authors have made similar recommendations in order to reduce the suicide rate and suicide attempts in sexual minority youth (Haas et al., 2001; Suicide Prevention Resource Center, 2008). Key among these policy recommendations are the explicit inclusion of sexual orientation in antibullying legislation and policies, as well as the establishment of sexual minority support programs such as school-based Gay-Straight Alliances (GSAs). However, researchers know very little about the impact of school-based GSAs on the mental health of sexual minority youth, especially at the population level (Heck, Flentje, \& Cochran, 2011; Walls, Kane, \& Wisneski, 2010).

\section{Review of the Literature}

A number of authors have drawn upon Emile Durkheim's classic typology of suicide to explain increased suicide risk in sexual minority youth. According to Durkheim (as cited in Thompson, 1982), suicide is not an individual act, it is a social act, and it is a function of both social integration and moral regulation (i.e., sociological factors). Durkheim (1897/2004) argued that different social groups, therefore, had different propensities towards suicide, for example, single people compared to married people. In addition, Durkheim posited four types of suicide: egoistic suicide, anomic suicide, altruistic suicide, and fatalistic suicide. Saunders and Valente (1987) concluded that sexual minority youth's alienation from society and societal rules lead to a sense of anomie, thus increasing the risk of anomic suicide. More recently, Kulkin, Chauvin, and Percle (2000) argued instead that a lack of connection to the social groups to which sexual minority youth belong (low social integration) increases the risk of egoistic suicide. Saunders and Valente considered a combined perspective: "Individuals who are estranged from social norms, disconnected from their social ties, and denied full participation in society, become progressively more isolated and alienated, and thus are more prone to suicide” (1987, p. 11).

Most researchers who study LGB youth health disparities have incorporated a broader model of social stigma and exclusion, based on Goffman's (1963) theory of stigma management, rather than Durkheim's more focused model of suicide. In a recent decade review of research, Saewyc (2011) concluded that the evidence of health disparities among sexual minority youth, including suicide, is more supportive of a stress-induced response based on theories of stigma and rejection than of other theories: "One of the most common explanations for health disparities among sexual minority adolescents is their exposure to stigma and discrimination, especially enacted stigma, that is, being targeted for bullying and harassment, exclusion, and violence” (p. 265). Numerous studies have found links between enacted stigma, or victimization, and increased health risk behaviours such as suicide (Waldo, Hesson-McInnis, \& D’Augelli, 1998), substance abuse (Bontempo \& D’Augelli, 2002), eating disordered behaviours (Woodford, Howell, Silverschanz, \& Yu, 2012), teen pregnancy involvement (Saewyc, Poon, Homma, \& Skay, 2008), and sexual victimization (Tyler, 2008).

One of the contexts in which sexual minority youth are prone to experiences of isolation, alienation, stress, and stigmatization is the school. As one example of how heterosexism leads to feelings of isolation and alienation, Woodford and colleagues (2012) examined the effects of hearing 
International Journal of Child, Youth and Family Studies (2014) 1: 89-112

“That's so gay!” on LGB college students. The authors argue this pejorative comment is an example of heterosexist micro-aggression that can lead to poor mental and physical health in sexual minority students. The study found that between $47 \%$ and $87 \%$ of participants reported hearing "That's so gay!" in the past year, with almost half hearing the expression 10 or more times, and most hearing it at least once. In addition, those sexual minority students who heard the expression more often also reported feeling left out on campus. These same students reported having more headaches and more eating problems than students who heard “That's so gay!” less often. Swearer and colleagues (2008) found comparable results in a presumably heterosexual sample. High school students who were bullied because of their perceived sexual orientation reported higher depression and more negative attitudes toward school than did students who were bullied on other grounds, although these authors did not measure sexual orientation, increasing the chance of confounding orientation and homophobic bullying. A similar report from Seattle's Youth Risk Behavior Survey, however, found that $70 \%$ of students who experienced anti-gay harassment actually identified as heterosexual, and they were just as likely as LGB youth who had experienced anti-gay harassment to feel school was unsafe, to skip school, and to engage in health compromising behaviours (Smyser \& Reis, 2002).

Given what researchers and educators know about the increased risks that sexual minority youth face in the school context, what are school boards and schools doing to ensure that these students are afforded a safe and equitable education? Recent school climate surveys conducted by GLSEN in the United States (Kosciw et al., 2010) and EGALE Canada (Taylor et al., 2011) have found that the majority of sexual minority students report frequent harassment and victimization at school, feeling unsafe and isolated at school, and low levels of school attachment and academic achievement. In some studies, sexual minority youth who attend schools with Gay-Straight Alliances (GSAs) report fewer negative and more positive school experiences compared to those who attend schools without GSAs, although this is not a consistent finding. For example, in the American survey, having a GSA at school was related to less victimization and less absenteeism as well as greater school attachment on the part of sexual minority students (Kosciw et al., 2010). Likewise, having explicit anti-homophobia policies at school was related to less victimization and a greater willingness to report incidents on the part of sexual minority youth. Similar results were found in the Canadian survey, especially with respect to having an explicit anti-homophobia policy at school (Taylor et al., 2011). Both of these studies used convenience samples, however, so the generalizability of findings is limited. A recent population-based study of schools in Wisconsin found no significant relationship between the presence of GSAs and homophobic victimization experiences (Poteat, Sinclair, DiGiovanni, Koenig, \& Russell, 2012); although the authors state the findings were in the right direction, the small number of schools involved may have reduced the power to detect effects.

In the United States, few school districts have adopted anti-discrimination policies that are inclusive of sexual orientation (Wald, Rienzo, \& Button, 2002). For example, even in American jurisdictions that have passed gay rights legislation, only a third (36\%) included schools as institutions protected under the legislation (Button, Rienzo, \& Wald, 1997). Over a decade later, researchers are still calling for explicit anti-discrimination school policies, arguing that such policies represent "the most important first step to challenge gender and sexuality norms and promote safe school climates” (Toomey, McGuire \& Russell, 2012, p. 189). However, there is limited evidence as to whether policies alone are enough; in the study by Toomey \& colleagues, having inclusive school policies was not a significant predictor of perceived safety, and the authors concluded that school policies are necessary but not sufficient in terms of improving the school climate for gender-nonconforming students. Given the cross- 
International Journal of Child, Youth and Family Studies (2014) 1: 89-112

sectional nature of the study, determining directionality was not possible. Nor did they consider the length of time since the policies had been implemented in measuring effects, although it can take time for policy changes to disseminate widely and actually alter school climates or student behaviours.

With respect to suicidality, some research has shown that sexual minority youth in schools with GSAs have a lower rate of suicidality than sexual minority youth in schools without GSAs (e.g., Goodenow et al., 2006), although the primary study was limited to a single American state (Massachusetts) with progressive societal attitudes about LGB people, as evidenced by it becoming the first state in the U.S. to legalize gay marriage. Another study among sexual minority youth receiving social services found attending a school with a GSA was related to having fewer suicidal thoughts and attempts (Walls, Freedenthal, \& Wisneski, 2008). More recently, a retrospective study of California young adults found that participation in a GSA during high school buffered the risk for lifetime suicide attempts, but only when levels of sexual minority victimization are low (Toomey, Ryan, Diaz, \& Russell, 2011). For those sexual minority young adults who reported high levels of victimization as students, participation in a GSA was related to a greater probability of attempting suicide. These authors point out, however, that as their variable of interest was "lifetime suicide attempts," these could have occurred prior to participation in a GSA.

In studying the impact of GSAs on the mental health of sexual minority youth, therefore, researchers have found inconsistencies (Toomey et al., 2011; Walls et al., 2010). The presence of a GSA at school is typically but not necessarily associated with positive outcomes for sexual minority students. Methodological differences no doubt account for some of these inconsistencies; for example, some studies are quantitative in design (e.g., Hatzenbeuhler, 2011; Heck et al., 2011) whereas others are qualitative (e.g., Russell, Muraco, Subramaniam, \& Laub, 2009). Some researchers have studied the effects of having a GSA at school (e.g., Szalacha, 2003; Goodenow et al., 2006); other researchers have studied the effects of participating in a GSA (e.g., Toomey et al., 2011; Walls et al., 2010). Some researchers have focused on LGB youth (e.g., Goodenow et al., 2006; Hatzenbeuhler 2011), while others have focused on gender-nonconforming youth (e.g., Toomey et al., 2012). All the studies we found to date have been conducted in the United States, most of them in relatively liberal or progressive states.

There is also the issue of who is both affected by homophobic school climates and might benefit from GSAs. Because heterosexual youth outnumber LGB youth so greatly, they can comprise half or more of those targeted with anti-gay harassment (Smyser \& Reis, 2001; Saewyc, Poon, et al., 2007), yet it is unclear whether the "straight" teens in schools with Gay-Straight Alliances benefit from them similarly.

GSAs alone are unlikely to change school climate (Goodenow et al., 2006; Walls et al., 2010). It may be that a more comprehensive approach is required, including GSAs as well as explicit antihomophobia and anti-transphobia policies, the inclusion of lesbian, gay, bisexual and transgender (LGBT) issues in the curriculum, and teachers who intervene when students are harassed or victimized (Kosciw et al., 2010; Taylor et al., 2011; Toomey et al., 2012). For example, Hatzenbuehler (2011) has examined suicidality in LGB youth as a function of their social environment at both the level of the school and the level of the community. In particular, Hatzenbuehler created a composite index of the social environment in 34 counties in Oregon, including the proportion of same-sex couples, the proportion of registered Democrats, school policies that explicitly protect sexual minority students, and the presence of GSAs in schools. The sexual minority youth who lived in unsupportive counties had a 
International Journal of Child, Youth and Family Studies (2014) 1: 89-112

$20 \%$ higher risk of suicide attempts compared to the sexual minority youth who lived in more supportive counties.

Thus, although much progress has been made over the past decade with respect to the volume and quality of research about suicidality among sexual minority youth, with beginning evidence for the effectiveness of some interventions, many unanswered questions remain. For example, are recommended interventions, such as GSAs, having the desired effect with respect to youth outcomes like suicide attempts in more places than progressive states on the east and west coasts of the United States? Do policy and GSA interventions affect the school experience and suicidality of all youth, or only sexual minority youth? Furthermore, given the correlational nature of most cross-sectional studies, researchers are limited in their ability to infer directionality or causality, while studies that use convenience samples limit researchers' ability to generalize more widely. Research is needed that can help address some of these further questions about the effectiveness of specific interventions to address the higher risk of suicidality among sexual minority youth.

\section{Purpose}

We used a population-based data set to examine the link between two school-district or schoollevel interventions (explicit anti-homophobic school policies and GSAs), on recent suicidal ideation and attempts among both sexual minority and heterosexual youth in Western Canada. In particular, we explored suicide ideation and suicide attempts as a function of two school-level interventions: having an explicit anti-homophobia school policy in the school district, and having a GSA in the school.

Furthermore, as it takes time for school policies and GSAs to take effect, we examine whether the length of time that interventions have been in place affects current student behaviours, by comparing students in schools with older established school policies and GSAs with students in schools with more recently established school policies and GSAs. This may help tease out the issue of the timing of intervention versus risk behaviour.

We hypothesized that, as with the preponderance of existing studies, LGB and mostly heterosexual students in the schools in our study would have higher prevalence than exclusively heterosexual students of homophobic discrimination, despair, suicidal ideation, and suicide attempts (H1). We also predicted that LGB students who attend schools with specific anti-homophobia policies or GSAs would have lower prevalence of homophobic discrimination, suicidal ideation or attempts compared to LGB students who attend schools without such policies or programs (H2). In addition, we expected that LGB students who attend schools with longer-established policies and GSAs would have lower rates of all these mental health challenges compared to LGB students who attend schools with no policies or GSAs, or with only recently established interventions (H3). Although there is no extant evidence to directly guide our hypotheses about mostly heterosexual or exclusively heterosexual students and policies or GSAs, we felt that an overall change in school climate driven by these types of anti-homophobic or inclusive programs would also benefit the mental health of other students in those schools, and that these two orientation groups would also be less likely to report suicidal ideation or attempts than mostly heterosexual or exclusively heterosexual students in schools without these policies or programs, or schools with more recently established programs (H4). 
International Journal of Child, Youth and Family Studies (2014) 1: 89-112

\section{Methods}

\section{Data Sources and Sample}

The present study was a secondary analysis of the 2008 British Columbia Adolescent Health Survey (BCAHS). This paper-and-pencil questionnaire was administered to a cluster-stratified random sample of more than 1,700 classes in Grades 7 to 12 in more than 450 public schools in British Columbia, Canada. The participating school districts represent $92 \%$ of enrolled students across the province. In consultation with Statistics Canada, the original data from 29,315 students were weighted to adjust for the differential probability of selection in the various regions, response rates, and proportion of enrollment. The University of British Columbia Behavioural Research Ethics Board approved both the original survey and this subsequent study.

The present study included only students who responded to a self-labelling measure defined by romantic attractions for sexual orientation that has been used in previous research (e.g., Saewyc, Bearinger, Blum, \& Resnick, 1999; Saewyc et al., 2006). The response options for this measure included 100\% heterosexual, mostly heterosexual, bisexual, mostly homosexual, 100\% homosexual (gay/lesbian), and not sure. The 100\% homosexual (gay/lesbian), mostly homosexual, and bisexual youth were grouped together to form an LGB sample for the present analyses. The mostly heterosexual group was kept as a separate sexual minority group, being both larger than the combined LGB group, and because of prior research that suggests this group differs from both exclusively heterosexual and also LGB groups in demographics and health disparities (Saewyc et al., 2004; Saewyc, 2011). As described earlier, previous research has also shown the presence of homophobic bullying and its negative effects among exclusively heterosexual or "straight" youth, but we do not know yet whether GSAs or anti-homophobic policies would contribute to the reduction of homophobic bullying or its negative effects for the heterosexual teens. Accordingly, the present analyses explored the roles of GSAs and policies not only for LGB and mostly heterosexual students but also the 100\% heterosexual teens. The "not sure" group was excluded from the present analyses, because several different possible reasons for choosing that option make it unclear how such students are responding to the item (Saewyc et al., 2004, provide a critical evaluation of "not sure" categories in several surveys). Seventh graders were also excluded in this study, because the majority of these students were enrolled in either elementary or middle schools, where GSAs have not been implemented in British Columbia. The final weighted sample in this study included 21,708 students. Given that sexual minority youth appeared to be sparsely and randomly distributed across the province, with no clustering within schools or classrooms, adjustments for the cluster-sampling design were considered unnecessary for these analyses (Poon \& Saewyc, 2009).

\section{Measures}

Homophobic discrimination. Experience of discrimination due to sexual orientation was measured with a single item: "In the past 12 months, have you been discriminated against or treated unfairly because of your sexual orientation (being or thought to be gay or lesbian)?” Responses were yes or no.

Suicide-related variables. The suicide-related variables included serious suicidal ideation and the number of suicidal attempts in the past year. Suicidal ideation responses were yes or no, while original response options to suicide attempt were "0 times”, " 1 time”, " 2 or 3 times”, “4 or 5 times”, and 
International Journal of Child, Youth and Family Studies (2014) 1: 89-112

“6 or more times” which were dichotomized into attempted or did not attempt suicide in the past year.

Despair. Despair, a proxy measure for depression symptoms, was assessed by asking if students had felt so sad, discouraged, hopeless, or had so many problems that they wondered if anything was worthwhile in the past 30 days. The ordinal response options included "Not at all", "A little", "Some, enough to bother me”, "Quite a bit”, and "Extremely so, to the point I couldn't do my work or deal with things”. Students who reported having felt these symptoms at an intensity that was enough to bother them, so much so that they had difficulty functioning, were classified as having despair. We included this proxy measure for depressive symptoms primarily as a control variable for the suicide outcomes; depression may have organic causes unrelated to discrimination or homophobic bullying, yet it is also strongly linked to suicidal ideation and attempts in the overall population (Evans, Hawton, \& Rodham, 2004).

\section{Procedures and Data Analyses}

In order to identify schools having GSAs or specific anti-homophobic bullying policies, the websites of schools that participated in the BCAHS were first examined for mention of policies or GSAs. In addition, schools with explicit homophobia-related anti-bullying policies were documented on the British Columbia Teachers' Federation website. Then schools were contacted by telephone to confirm the presence or absence of GSAs and specific policies, and to learn the year in which they were first implemented, if that was not already provided. For these analyses, schools were classified into those with no GSA and/or policies, those with recently established GSAs or policies (i.e., implemented within the past 3 years, between 2005 and 2007) versus those with longer-term GSAs or policies (i.e., more than 3 years, or before 2005). Subsequently, the information about GSAs and school-district antihomophobia policies was linked to the BCAHS data of individual students in the relevant schools.

SPSS version 19.0 was used for all statistical analyses in this study. Prevalence comparisons between LGB and mostly heterosexual students to heterosexual students with regard to suicidal outcomes, experiences of discrimination, and school characteristics were performed using chi-square tests. Logistic regressions examined the hypothesized effects of GSAs and policies on suicidal behaviours and sexual orientation discrimination among LGB, mostly heterosexual, and heterosexual students separately; the regression models for suicidal outcomes included covariates to control for potential confounders (e.g., level of despair). For evaluating the effects of timing of GSAs and policies, we used multinomial logistic regression models for each orientation group, with no GSA or no policy as the referent group. We also conducted multinomial regressions focused on evaluating the combinations of GSA, policy, or both on the three main outcomes; however, because schools may implement only GSAs and policies, or both in different years, the permutations rendered it infeasible to conduct multinomial regression models incorporating length of time since program or policy was implemented. Given the well-documented gender differences of health and risk behaviours (Saewyc, Bearinger, Heinz, Blum, \& Resnick, 1998), we conducted all analyses separately by gender. Among both boys and girls, LGB and mostly heterosexual students were significantly older on average, and there were significantly larger percentages of LGB and mostly heterosexual youth in the older grades (boys, $\chi^{2}=21.43, p<.001$; girls, $\chi^{2}=22.72, p<.011$ ). This is commonly found in population surveys, as sexual identity is a developmental task of adolescence, and younger adolescents who have not begun to feel sexual attractions tend to choose the "default" heterosexual identity, although they may change identity labels 
International Journal of Child, Youth and Family Studies (2014) 1: 89-112

as they get older (Ott, Corlyss, Wypij, Rosario, \& Austin, 2011). To address this maturational issue, we controlled all analyses by grade.

\section{Results}

As shown in Table 1, the majority of students identified themselves as $100 \%$ heterosexual (weighted $n=10,408$ for boys; weighted $n=10,577$ for girls) as compared to mostly heterosexual (weighted $n=840$ for boys; weighted $n=914$ for girls) or LGB (weighted $n=359$ for boys; weighted $n$ = 364 for girls). A similar proportion of LGB, mostly heterosexual, and heterosexual youth were enrolled in schools with GSAs and with explicit school district anti-bullying policies, although mostly heterosexual youth were slightly more likely to be in schools with GSAs and explicit policies.

\section{Hypothesis 1: Differences in prevalence of discrimination, suicidal ideation and attempts}

As hypothesized, LGB and mostly heterosexual boys and girls were more likely to report despair in the past month compared to exclusively heterosexual students, and they also reported a significantly higher prevalence of sexual orientation discrimination in the past year (Table 1). Because exclusively heterosexual students comprise a much higher portion of the overall student population, however, the small proportion of them who had experienced discrimination because others thought they were gay or lesbian represents an equal or larger actual number of students compared to LGB or mostly heterosexual students (385 exclusively heterosexual boys versus 181 gay/bisexual boys and 143 mostly heterosexual boys; 138 exclusively heterosexual girls versus 140 lesbian/bisexual girls and 80 mostly heterosexual girls).

As expected, both LGB and mostly heterosexual students (boys and girls) were significantly more likely than heterosexual peers to report serious suicidal ideation (also Table 1). Fully 1 in 3 gay and bisexual boys and 1 in 4 mostly heterosexual boys reported ideation in the past year compared to fewer than 1 in 10 exclusively heterosexual boys; nearly half of lesbian and bisexual girls and 1 in 4 mostly heterosexual girls said they seriously thought about suicide, as compared to just over 1 in 9 exclusively heterosexual girls. The disparity in past year suicide attempts was even more striking for sexual minority students compared to their heterosexual peers, as more than 1 in 4 LGB boys or girls and 1 in 10 mostly heterosexual students had attempted suicide in the past year, while fewer than 5\% of exclusively heterosexual students had done so.

\section{Hypotheses 2 (and 4): Presence of GSAs and/or anti-homophobia policies reduces sexual orientation discrimination and suicidality}

First we examined the potential links between the presence of a GSA, or explicit antihomophobic bullying policies, and sexual orientation discrimination or suicidal responses for LGB, mostly heterosexual, and exclusively heterosexual youth (Table 2). Then we examined the various combinations of GSA, policy, or both on these outcomes for each of the orientation groups. As shown in Table 2, GSAs in schools were associated with lower odds of sexual orientation discrimination for both LGB boys and girls, and mostly heterosexual girls. GSAs were only linked to reduced odds of suicidal ideation for mostly heterosexual girls, but none of the orientation groups had significantly reduced odds of past year suicide attempts, although all but one of the odds ratios was in the right direction. Explicit anti-homophobic bullying policies were associated with lower odds of discrimination for mostly 
International Journal of Child, Youth and Family Studies (2014) 1: 89-112

heterosexual girls, suicidal ideation for exclusively heterosexual girls, and suicide attempts for LGB boys and girls.

The majority of students (59.2\%) attended schools with neither a GSA nor an anti-homophobic bullying policy; 20.6\% attended schools with GSAs but no policy, 8.6\% attended schools with antihomophobic bullying policies but no GSAs, and 11.6\% attended schools with both GSAs and policies. Table 3 shows the adjusted odds of discrimination, suicidal ideation and attempts comparing the different combinations of GSA and policy for LGB youth. LGB boys in schools having both a GSA and an anti-homophobic bullying policy reported significantly lower odds of discrimination, while LGB girls reported significantly lower odds of discrimination, suicidal ideation, and suicide attempts. Among mostly heterosexual students, having both a GSA and an explicit policy was only linked to lower sexual orientation discrimination for girls. For exclusively heterosexual students, no combination of GSA and/or policy was linked to reduced odds of discrimination or suicidality, although the adjusted odds ratios were slightly less than 1 in nearly every combination (data not shown).

\section{Hypotheses 3 (and 4): Length of time GSAs or anti-homophobia policies have been implemented influences discrimination and suicidality}

Since it can take time for policies and programs to have a widespread effect within a school, we also examined the relationship between length of time since they were first implemented and the discrimination and suicide outcomes among each orientation group. Table 4 presents the results of multinomial logistic regression analyses for sexual orientation discrimination and suicidality among LGB students, Table 5 shows the same results for mostly heterosexual students, and Table 6 shows the results for exclusively heterosexual students.

Students in schools with longer-established GSAs (i.e., more than 3 years since implementation) had significantly reduced odds of all of the outcome measures (i.e., homophobic discrimination, suicidal ideation, suicide attempts) for LGB boys and girls, except for suicide attempts among boys. The odds of discrimination, suicidal ideation, and suicide attempts were reduced by more than half with longerestablished GSAs compared to no GSA. However, having a recently established GSA (i.e., one that was implemented between 2005 and 2007) did not predict lower odds of suicidal ideation, suicide attempts, or discrimination. For mostly heterosexual students, a GSA that had been in place for 3 or more years was linked to significantly lower odds of sexual orientation discrimination for both boys and girls, but only lower odds of suicidal ideation for mostly heterosexual girls; having a recently established GSA was not associated with reduced odds of discrimination or suicidality.

The presence of longer-term anti-homophobic bullying policies was also associated with lower odds of suicidal ideation and suicide attempts for gay and bisexual boys, and lower probability of suicide attempts for lesbian and bisexual girls, but not to discrimination. Recently established antibullying policies were not significantly associated with homophobic discrimination or suicidality among LGB adolescents. In contrast, for mostly heterosexual students, policies that had been in place for 3 or more years were associated with lower odds of discrimination for girls, but not boys, and were not linked to the suicide variables for either boys or girls. Recently established policies had no significant relationships to discrimination, suicidal ideation, or suicide attempts. 
International Journal of Child, Youth and Family Studies (2014) 1: 89-112

What about the "straight" members of gay-straight alliances, those who identify as exclusively heterosexual? Schools with a longer history of GSA or an explicit homophobia-related anti-bullying policy were also significantly linked to lower odds of suicidality among exclusively heterosexual adolescent boys, but not girls (Table 6). Heterosexual boys in schools whose GSAs had been in existence for more than 3 years were about half as likely as those in schools without GSAs to attempt suicide (AOR $=0.52$ ), and boys in schools with longer-established specific anti-bullying policies were about 25\% less likely to experience suicidal ideation compared to boys in schools with no policies (AOR $=0.72$ ). These results were not found for exclusively heterosexual girls, and similar to the results for sexual minority adolescents, neither recently established GSAs nor recently established policies were linked to a lower probability of suicidal ideation, suicide attempts, or discrimination among heterosexual boys and girls.

\section{Discussion}

In this study of sexual minority and heterosexual students in Grades 8 through 12 throughout the Province of British Columbia, on the west coast of Canada, LGB and mostly heterosexual students in schools with specific anti-homophobic bullying policies and schools with GSAs had lower odds of recent sexual orientation discrimination, suicidal thoughts, and suicide attempts, primarily when both were implemented, or when the policies and GSAs had been in place for 3 years or more. This suggests that the presence of a GSA, or the existence and enforcement of specific anti-bullying policies, may influence the overall school climate enough to reduce discrimination and other stressors among sexual minority youth and, in turn, may help prevent suicidal ideation and suicide attempts. These results affirm the results from the first such study, in Massachusetts schools (Goodenow et al., 2006), but may also help explain the equivocal results in some prior studies in the United States (Toomey et al., 2012; Poteat et al., 2012); the length of time since the policies or GSAs had been implemented was not included in those studies, and so it might have been too soon after the initiation of some programs to influence school environments enough to reduce suicidal ideation and attempts among LGB and mostly heterosexual youth in those schools. At the same time, explicit policies had a less consistent protective effect than GSAs did, which suggests, as Toomey and colleagues concluded, that they may be an important but not sufficient school-based intervention to help prevent suicidality among sexual minority adolescents.

As ours is one of the first studies to consider the potential effects of these interventions for mostly heterosexual and exclusively heterosexual adolescents as well as LGB youth, we feel it is important to consider the gender difference in these effects. Mostly heterosexual girls, but not boys, and exclusively heterosexual boys, but not girls, had lower odds of suicidal ideation and attempts in schools with anti-homophobic bullying policies and GSAs. While the reasons for these gender differences are not clear, one possible explanation, found in observational research among younger adolescents, is that homophobic bullying is more commonly used by boys as a way of enforcing dominant norms of masculinity and status in their peer groups (McGuffey \& Rich, 1999), even towards other heterosexual boys. This was also the case in our study, where exclusively heterosexual boys were more than twice as likely to report sexual orientation discrimination than exclusively heterosexual girls, although both of these were small percentages compared to sexual minority groups.

To the extent that homophobic bullying is outlawed and the policy is enforced, or where GSAs offer supportive space for other performances of masculinity, this may create a less stigmatizing space 
International Journal of Child, Youth and Family Studies (2014) 1: 89-112

for exclusively heterosexual boys who do not fit the stereotypes of hegemonic masculine behaviour. This is just one possibility, and other reasons may include a lack of power to detect significant differences between rarely occurring events (suicide attempts) and rarely occurring predictors (sexual orientation discrimination) for this group; however, it is important to recognize that heterosexual boys and girls who reported the sexual orientation discrimination were more likely to report suicidal ideation and attempts than their peers who did not experience that discrimination. Further research is needed to understand how anti-homophobic policies and programs may influence heterosexual boys' and girls' school experiences and suicidality.

While the results of our study are promising as evidence of the potential benefits of GSAs and specific policies to reduce stigma and suicide among adolescents in school, there are some limitations to the research that should be noted, and potential challenges to implementing such programs to be considered. Although we had information about when the GSAs were first implemented, we had no other details about the GSAs, their size and visibility in the schools, and their purpose. The type of GSA, that is, whether a social support club as opposed to a social justice club (Russell et al., 2009), may influence its effectiveness in reducing discrimination and emotional distress among LGB youth. The perceived effectiveness of the GSA within the school, and the amount of time that students actually spend involved in a GSA, could similarly affect their outcomes (Toomey et al., 2011).

As well, while we found a potential additive effect of having both GSAs and policies in place in schools, we could not incorporate into that analysis the length of time since they were implemented, as this created too many permutations for adequate power within our sample. It is possible that the effects shown among the combinations of GSAs and policies would be stronger among longer-established GSAs and policies as opposed to recently established programs.

Likewise, this is still a primarily cross-sectional study, in that students were only assessed at one point in time, albeit with recent discrimination and suicidal behaviours, and the timing of the GSAs and policies in schools. In contrast, examining school climate and youth suicidality before and after a policy or program was implemented, perhaps by using successive waves of data from population surveys, would offer stronger evidence that interventions were having the desired effects.

Given the consistently documented higher risk for suicidal ideation and attempts among sexual minority adolescents, prevention efforts should be a priority for this population, and population-level interventions in schools may be an efficient way of addressing this health inequity. At the same time, it requires the willingness of schools and school districts to enact these policies and programs, and some schools and school districts may not be supportive of GSAs (Walls et al., 2010).

Recently, the legislature of the Province of Ontario passed Bill 13, an anti-bullying act, which stipulates that school boards and principals cannot refuse to allow GSAs in Ontario schools: "neither the board nor the principal shall refuse to allow a pupil to use the name gay-straight alliance or a similar name” (Bill 13, 303.1[2], 2012). Catholic bishops have voiced serious concerns about this new legislation, as they feel the purpose of GSAs is in conflict with Roman Catholic values (Howlett, 2012). That our results suggest GSAs could also be helpful in reducing suicidal ideation among heterosexual students may serve to reduce some of the opposition, and may offer an opportunity for school district staff, who are themselves supportive, to provide evidence to reassure concerned parents or elected school trustees. 
More research is needed to understand the specific mechanisms by which GSAs and antihomophobic bullying policies influence suicidal ideation and attempts: Is it through changing the school climate, by reducing stigma, harassment, and discrimination? Or do these population-level interventions promote school connectedness, a sense of belonging and feeling safe and supported, among students? As well, while suicide prevention is an important focus, do these strategies also have influence on other health disparities amongst LGB, mostly heterosexual, or exclusively heterosexual youth?

Gay-Straight Alliances, and specific anti-homophobic bullying policies, appear to be two important school-based interventions to help prevent anti-gay discrimination, suicidal ideation, and suicide attempts among lesbian, gay, and bisexual adolescents, as well as having some effect for mostly heterosexual girls and exclusively heterosexual boys. The potential effect is not small; although LGB youth generally have twice or greater the odds of suicidal behaviour than their heterosexual peers, each of these interventions, where they had been in place for a few years, reduced those odds by half or more. Schools have a responsibility to create safe and supportive environments for all their students, and these interventions are two strategies that may help some of their most vulnerable students survive. Given how long it may take for their effects to be felt throughout the school, there is no time to lose. 
International Journal of Child, Youth and Family Studies (2014) 1: 89-112

Table 1.

School characteristics and experiences by sexual orientation and gender

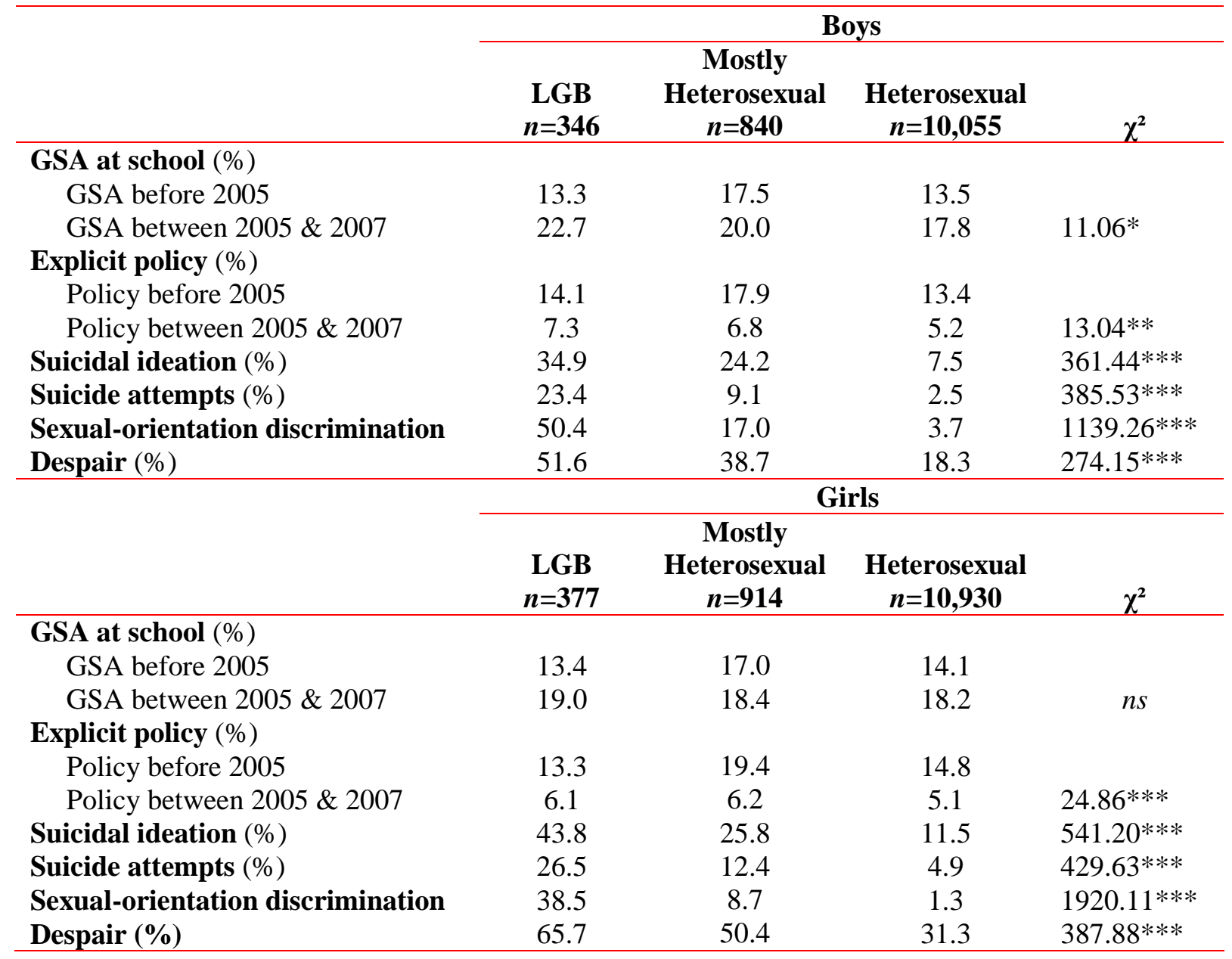

Notes: All $n$ s are weighted, ${ }^{*} p<.05 .{ }^{* *} p<.01 .{ }^{* * *} p<.001$. 
International Journal of Child, Youth and Family Studies (2014) 1: 89-112

Table 2.

Relationship between presence of GSAs or explicit school district policy, sexual orientation discrimination and suicidal outcomes among LGB, mostly heterosexual and 100\% heterosexual youth

\begin{tabular}{|c|c|c|c|c|c|c|}
\hline \multirow[b]{3}{*}{ GSAs } & \multicolumn{2}{|c|}{$\begin{array}{c}\text { Sexual orientation } \\
\text { discrimination }\end{array}$} & \multicolumn{2}{|c|}{ Suicidal ideation } & \multicolumn{2}{|c|}{ Suicide attempts } \\
\hline & AOR & $95 \%$ CI & AOR & $95 \% \mathrm{CI}$ & AOR & $95 \%$ CI \\
\hline & & & & & & \\
\hline LGB Boys & $0.47 *$ & $(0.26-0.84)$ & 0.79 & $(0.39-1.58)$ & 0.68 & $(0.32-1.45)$ \\
\hline LGB Girls & $0.61 *$ & $(0.40-0.93)$ & 0.66 & $(0.42-1.05)$ & 0.72 & $(0.43-1.21)$ \\
\hline Mostly Het Boys & 0.65 & $(0.37-1.14)$ & 0.74 & $(0.45-1.24)$ & 0.83 & $(0.41-1.67)$ \\
\hline Mostly Het Girls & $0.60^{*}$ & $(0.37-0.97)$ & $0.68 *$ & $(0.49-0.95)$ & 1.04 & $(0.68-1.57)$ \\
\hline 100\% Het Boys & 0.97 & $(0.761 .24)$ & 0.90 & $(0.75-1.08)$ & 0.86 & $(0.63-1.16)$ \\
\hline 100\% Het Girls & 0.88 & $(0.59-1.32)$ & 0.86 & $(0.74-1.00)$ & 0.95 & $(0.77-1.18)$ \\
\hline Explicit SD polic & & & & & & \\
\hline LGB Boys & 0.59 & $(0.31-1.13)$ & 0.51 & $(0.23-1.10)$ & $0.38 *$ & $(0.15-0.97)$ \\
\hline LGB Girls & 0.75 & $(0.46-1.21)$ & 0.73 & $(0.44-1.23)$ & $0.55^{*}$ & $(0.30-0.99)$ \\
\hline Mostly Het Boys & 0.94 & $(0.53-1.67)$ & 1.07 & $(0.63-1.84)$ & 0.62 & $(0.27-1.40)$ \\
\hline Mostly Het Girls & $0.39 * *$ & $(0.22-0.70)$ & 0.98 & $(0.71-1.37)$ & 1.03 & $(0.69-1.56)$ \\
\hline 100\% Het Boys & 0.99 & $(0.76-1.30)$ & 0.84 & $(0.69-1.03)$ & 0.91 & $(0.65-1.27)$ \\
\hline 100\% Het Girls & 0.93 & $(0.61-1.44)$ & $0.84 *$ & $(0.72-0.99)$ & 0.99 & $(0.78-1.24)$ \\
\hline
\end{tabular}

Notes: Statistically significant results in bold ${ }^{*} p<.05 .{ }^{* *} p<.01 .{ }^{* * *} p<.001$.

Reference categories: No GSAs; No Explicit SD policy.

Adjusted for grade.

Control variable(s) for suicide-related outcomes: feelings of despair (Note: not for sexual-orientation discrimination). 
International Journal of Child, Youth and Family Studies (2014) 1: 89-112

\section{Table 3.}

Comparing influences of combinations of GSAs \& explicit anti-homophobic bullying policy on sexual orientation discrimination and suicidality among LGB Youth

\begin{tabular}{|c|c|c|c|c|c|c|}
\hline & \multicolumn{2}{|c|}{$\begin{array}{l}\text { Sexual-orientation } \\
\text { discrimination }\end{array}$} & \multicolumn{2}{|c|}{ Suicidal ideation } & \multicolumn{2}{|c|}{ Suicide attempts } \\
\hline & AOR & $95 \%$ CI & AOR & $95 \%$ CI & AOR & $95 \%$ CI \\
\hline \multicolumn{7}{|l|}{ Boys } \\
\hline Neither GSAs nor policy & ref & & ref & & ref & \\
\hline GSAs only & 0.52 & $(0.26-1.05)$ & 1.39 & $(0.60-3.20)$ & 0.87 & $(0.36-2.08)$ \\
\hline Explicit policy only & 1.03 & $(0.39-2.73)$ & 1.48 & $(0.43-5.13)$ & 0.44 & $(0.10-2.04)$ \\
\hline Both GSAs and policy & $0.36 *$ & $(0.15-0.89)$ & 0.34 & $(0.11-1.03)$ & 0.31 & $(0.09-1.15)$ \\
\hline \multicolumn{7}{|l|}{ Girls } \\
\hline Neither GSAs nor policy & ref & & ref & & ref & \\
\hline GSAs only & 0.71 & $(0.42-1.19)$ & 0.89 & $(0.51-1.53)$ & 1.09 & $(0.61-1.96)$ \\
\hline Explicit policy only & 1.04 & $(0.51-2.14)$ & 1.25 & $(0.57-2.74)$ & 1.01 & $(0.46-2.22)$ \\
\hline Both GSAs and policy & $0.46 *$ & $(0.23-0.92)$ & $0.41 *$ & $(0.20-0.85)$ & $0.29 *$ & $(0.11-0.76)$ \\
\hline
\end{tabular}

Notes: Statistically significant results in bold ${ }^{*} p<.05 .{ }^{* *} p<.01 .{ }^{* * *} p<.001$.

Reference categories: Neither GSAs nor Explicit SD policy.

Adjusted for grade.

Control variable(s) for suicide-related outcomes: feelings of despair (Note: not for sexual-orientation discrimination). 
International Journal of Child, Youth and Family Studies (2014) 1: 89-112

Table 4.

Relationship between timing of implementing GSAs or explicit anti-homophobia policy, sexual orientation discrimination and suicidal outcomes among LGB youth

\begin{tabular}{|c|c|c|}
\hline $\begin{array}{c}\text { Sexual orientation } \\
\text { discrimination }\end{array}$ & Suicidal ideation $^{\mathrm{a}}$ & Suicide attempts ${ }^{\mathrm{a}}$ \\
\hline $95 \%$ CI & $95 \%$ CI & $95 \%$ CI \\
\hline
\end{tabular}

GSAs

Boys

GSAs between 2005 \& $2007 \quad 0.61 \quad(0.31-1.23) \quad 1.63 \quad(0.74-3.62) \quad 0.79 \quad(0.34-1.86)$

$\begin{array}{lllllll}\text { GSAs before } 2005 & \mathbf{0 . 3 0 * *} & (0.12-0.72) & \mathbf{0 . 0 7} * * & (0.01-0.51) & 0.47 & (0.13-1.71)\end{array}$

Girls

GSAs between $2005 \& 2007 \quad 0.72 \quad(0.44-1.20) \quad 0.87 \quad(0.50-1.52) \quad 1.00 \quad(0.55-1.83)$

GSAs before $2005 \quad \mathbf{0 . 4 6}^{*} \quad(0.24-0.87) \quad \mathbf{0 . 4 4}^{*} \quad(0.23-0.86) \quad \mathbf{0 . 4 1}^{*} \quad(0.18-0.94)$

\section{Explicit SD policy}

Boys

Policy between $2005 \& 2007 \quad 0.90 \quad(0.33-2.44) \quad 1.31 \quad(0.42-4.04) \quad 0.56 \quad(0.15-2.01)$

Policy before $2005 \quad 0.47 \quad(0.22-1.03) \quad \mathbf{0 . 2 4}^{*} \quad(0.08-0.73) \quad \mathbf{0 . 2 7} * \quad(0.07-1.01)$

Girls

Policy between $2005 \& 2007 \quad 0.78 \quad(0.35-1.73) \quad 0.70 \quad(0.29-1.70) \quad 1.27 \quad(0.52-3.09)$

$\begin{array}{lllllll}\text { Policy before } 2005 & 0.74 & (0.42-1.30) & 0.75 & (0.41-1.35) & \mathbf{0 . 3 3} * * & (0.15-0.73)\end{array}$

Notes: Statistically significant results in bold ${ }^{*} p<.05 .{ }^{*} p<.01 .{ }^{* * *} p<.001$. Reference categories: No GSAs; No Explicit SD policy. All analyses Adjusted for grade.

${ }^{\mathrm{a}}$ Control variables for suicide-related outcomes also included feelings of despair, but not for discrimination. 
International Journal of Child, Youth and Family Studies (2014) 1: 89-112

\section{Table 5.}

Relationship between timing of implementing GSAs, explicit anti-homophobia school district policy, sexual orientation discrimination and suicidal outcomes among mostly heterosexual youth

\begin{tabular}{|c|c|c|c|c|c|c|}
\hline & \multicolumn{2}{|c|}{$\begin{array}{c}\text { Sexual orientation } \\
\text { discrimination }\end{array}$} & \multicolumn{2}{|c|}{ Suicidal ideation } & \multicolumn{2}{|c|}{ Suicide attempts } \\
\hline & AOR & $95 \% \mathrm{CI}$ & AOR & 95\% CI & AOR & $95 \%$ CI \\
\hline \multicolumn{7}{|l|}{ GSAs } \\
\hline \multicolumn{7}{|l|}{ Boys } \\
\hline GSAs between 2005 \& 2007 & 1.18 & $(0.64-2.17)$ & 0.63 & $(0.33-1.21)$ & 0.98 & $(0.43-2.22)$ \\
\hline GSAs before 2005 & $0.17 * *$ & $(0.05-0.57)$ & 0.90 & $(0.46-1.75)$ & 0.65 & $(0.24-1.80)$ \\
\hline \multicolumn{7}{|l|}{ Girls } \\
\hline GSAs between 2005 \& 2007 & 0.70 & $(0.39-1.26)$ & 0.77 & $(0.51-1.17)$ & 1.35 & $(0.82-2.22)$ \\
\hline GSAs before 2005 & $0.50^{*}$ & $(0.25-0.99)$ & $0.58 *$ & $(0.37-0.92)$ & 0.72 & $(0.39-1.33)$ \\
\hline \multicolumn{7}{|l|}{ Explicit SD policy } \\
\hline Policy between 2005 \& 2007 & 1.31 & $(0.53-3.24)$ & 0.87 & $(0.33-2.32)$ & 1.25 & $(0.38-4.12)$ \\
\hline Policy before 2005 & 0.81 & $(0.41-1.60)$ & 1.15 & $(0.63-2.09)$ & 0.43 & $(0.15-1.23)$ \\
\hline \multicolumn{7}{|l|}{ Girls } \\
\hline Policy between 2005 \& 2007 & 0.66 & $(0.27-1.01)$ & 1.42 & $(0.79-2.55)$ & 1.22 & $(0.58-2.56)$ \\
\hline Policy before 2005 & $0.31 * *$ & $(0.15-0.64)$ & 0.87 & $(0.60-1.26)$ & 0.98 & $(0.62-1.55)$ \\
\hline
\end{tabular}

Notes: Statistically significant results in bold ${ }^{*} p<.05 .{ }^{* *} p<.01 .{ }^{* * *} p<.001$.

Reference categories: No GSAs; No Explicit SD policy.

Adjusted for grade.

Control variable(s) for suicide-related outcomes: feelings of despair (Note: not for homophobic discrimination). 
International Journal of Child, Youth and Family Studies (2014) 1: 89-112

\section{Table 6.}

Relationship between timing of implementing GSAs or explicit anti-homophobia policy, sexual orientation discrimination and suicidal outcomes among exclusively heterosexual youth

\begin{tabular}{|c|c|c|}
\hline $\begin{array}{c}\text { Sexual orientation } \\
\text { discrimination }\end{array}$ & Suicidal ideation $^{\mathbf{a}}$ & Suicide attempts \\
\hline $95 \% \mathrm{CI}$ & $95 \%$ CI & $95 \% \mathrm{CI}$ \\
\hline
\end{tabular}

GSAs

Boys

GSAs between 2005 \& 2007

$\begin{array}{llllll}1.02 & (0.76-1.37) & 0.98 & (0.79-1.22) & 1.17 & (0.83-1.65) \\ 0.90 & (0.64-1.28) & 0.81 & (0.63-1.04) & \mathbf{0 . 5 2 * *} & (0.32-0.85)\end{array}$

GSAs before 2005

Girls

$\begin{array}{lllllll}\text { GSAs between 2005 \& } 2007 & 0.88 & (0.54-1.46) & 0.89 & (0.74-1.07) & 0.96 & (0.74-1.26) \\ \text { GSAs before 2005 } & 0.88 & (0.50-1.54) & 0.83 & (0.67-1.01) & 0.93 & (0.69-1.25)\end{array}$

\section{Explicit SD policy}

Boys

$\begin{array}{lcccccc}\text { Policy between 2005 \& } 2007 & 0.74 & (0.43-1.26) & 1.19 & (0.86-1.67) & 1.27 & (0.75-2.17) \\ \text { Policy before 2005 } & 1.09 & (0.81-1.47) & \mathbf{0 . 7 2 * *} & (0.57-0.93) & 0.78 & (0.52-1.17) \\ \text { Girls } & & & & & & \\ \text { Policy between 2005 \& 2007 } & 0.65 & (0.25-1.65) & 0.84 & (0.62-1.14) & 1.26 & (0.86-1.86) \\ \text { Policy before 2005 } & 1.04 & (0.65-1.66) & 0.84 & (0.70-1.02) & 0.89 & (0.68-1.17)\end{array}$

Notes: Statistically significant results in bold ${ }^{*} p<.05 .{ }^{* *} p<.01 .{ }^{* *} p<.001$. Reference categories: No GSAs; No Explicit SD policy. All analyses Adjusted for grade.

${ }^{\mathrm{a}}$ Control variables for suicide-related outcomes also included feelings of despair, but not for discrimination. 
International Journal of Child, Youth and Family Studies (2014) 5(1): 89-112

\section{References}

Bill 13, Accepting Schools Act, Ontario S.O. 2012 C.5 (2012).

Birkitt, M., Espelage, D. L., \& Koenig, B. (2009). LGB and questioning students in schools: The moderating effects of homophobic bullying and school climate on negative outcomes. Journal of Youth and Adolescence, 38(7), 989-1000. http://dx.doi.org/10.1007/s10964-008-9389-1

Bontempo, D. E., \& D’Augelli, A. R. (2002). Effects of at-school victimization and sexual orientation on lesbian, gay, or bisexual youths' health risk behavior. Journal of Adolescent Health, 30(5), 364-374. http://dx.doi.org/10.1016/s1054-139x(01)00415-3

Button, J. W., Rienzo, B. A., \& Wald, K. D. (1997). Private lives, public conflicts: Battles over gay rights in American communities. Washington, DC: Congressional Quarterly Press. http://dx.doi.org/10.5860/choice.35-0566

Coker, T. R., Austin, S. B., \& Schuster, M. A. (2010). The health and health care of lesbian, gay and bisexual adolescents. Annual Review of Public Health, 31, 457-477. http://dx.doi.org/10.1146/annurev.publhealth.012809.103636

D’Augelli, A. R., Pilkington, N. W., \& Hershberger, S. L. (2002). Incidence and mental health impact of sexual orientation victimization of lesbian, gay, and bisexual youths in high school. School Psychology Quarterly, 17(2), 148-167. http://dx.doi.org/10.1521/scpq.17.2.148.20854

Durkheim, E. (1897/2004). Reading 6: Suicide. (M. Thompson, Trans.). In K. Thompson (Ed.), Readings from Emile Durkheim (Rev. ed., pp. 81-106). New York: Routledge.

Eisenberg, M. E., \& Resnick, M. D. (2006). Suicidality among gay, lesbian and bisexual adolescents: The role of protective factors. Journal of Adolescent Health, 39(5), 662-668. http://dx.doi.org/10.1016/j.jadohealth.2006.04.024

Eskin, M., Kaynak-Demir, H., \& Demir, S. (2005). Same-sex sexual orientation, childhood sexual abuse, and suicidal behavior in university students in Turkey. Archives of Sexual Behavior, 34(2), 185195. http://dx.doi.org/10.1007/s10508-005-1796-8

Evans, E., Hawton, K., \& Rodham, K. (2004). Factors associated with suicidal phenomena in adolescents: A systematic review of population-based studies. Clinical Psychology Review, 24, 957-979. http://dx.doi.org/10.1016/j.cpr.2004.04.005

Galliher, R. V., Rostosky, S. S., \& Hughes, H. K. (2004). School belonging, self-esteem, and depressive symptoms in adolescents: An examination of sex, sexual attraction status, and urbanicity. Journal of Youth and Adolescence, 33(3), 235-245. http://dx.doi.org/10.1023/b:joyo.0000025322.11510.9d

Goffman, E. (1963). Stigma: Notes on the management of spoiled identity. Englewood Cliffs, NJ: Prentice-Hall. http://dx.doi.org/10.1136/pgmj.45.527.642

Goodenow, C., Szalacha, L., \& Westheimer, K. (2006). School support groups, other school factors, and the safety of sexual minority adolescents. Psychology in the Schools, 43(5), 573-589.

http://dx.doi.org/10.1002/pits.20173 
International Journal of Child, Youth and Family Studies (2014) 1: 89-112

Haas, A. P., Eliason, M., Mays, V. M., Mathy, R. M., Cochran, S. D., D'Augelli, A. R., et al. (2001). Suicide and suicide risk in lesbian, gay, bisexual, and transgender populations: Review and recommendations. Journal of Homosexuality, 58, 10-51. http://dx.doi.org/10.1080/00918369.2011.534038

Hatzenbeuhler, M. L. (2011). The social environment and suicide attempts in lesbian, gay, and bisexual youth. Pediatrics, 127(5). Retrieved from http://pediatrics.aappublications.org/content/early/2011/04/18/peds.2010-3020.full.pdf+html http://dx.doi.org/10.1542/peds.2010-3020

Heck, N. C., Flentje, A., \& Cochran, B. N. (2011). Offsetting risks: High school gay-straight alliances and lesbian, gay, bisexual, and transgender youth. School Psychology Quarterly, 26(2), 161-174. http://dx.doi.org/10.1037/a0023226

Homma Y., \& Saewyc E.M. (2007). The emotional well-being of Asian-American sexual minority youth in school. Journal of LGBT Health Research, 3(1), 67-78. http://dx.doi.org/10.1300/j463v03n01_08

Horn, S. S., Kosciw, J. G., \& Russell, S. T. (2009). Special issue introduction: New research on lesbian, gay, bisexual, \& transgender youth: Studying lives in context. Journal of Youth and Adolescence, 38(7), 863-866. http://dx.doi.org/10.1007/s10964-009-9420-1

Howlett, K. (2012, June 5). Anti-bullying bill passes, clearing way for gay-straight alliances in Ontario schools. The Globe and Mail. Retrieved from

http://www.theglobeandmail.com/news/politics/anti-bullying-bill-passes-clearing-way-for-gaystraight-alliances-in-ontario-schools/article4231542/

King, M., Semlyn, J., Tai, S. S., Killaspy, H., Osborn, D., Popelyuk, D., \& Nazareth, I. (2008). A systematic review of mental disorder, suicide, and deliberate self harm in lesbian, gay, and bisexual people. BMC Psychiatry, 8, 70. Retrieved from http://www.biomedcentral.com/1471244X/8/70 http://dx.doi.org/10.1186/1471-244x-8-70

Kosciw, J. G., Greytak, E. A., Diaz, E. M., \& Bartkiewicz, M. J. (2010). The 2009 National School Climate Survey: The experiences of lesbian, gay, bisexual, and transgender youth in our nation's schools. New York: GLSEN.

Kulkin, H. S., Chauvin, E. A., \& Percle, G. A. (2000). Suicide among gay and lesbian adolescents and young adults. Journal of Homosexuality, 40, 1-29. http://dx.doi.org/10.1300/j082v40n01_01

Lucassen, M. F. G., Merry, S. N., Robinson, E. M., Denny, S., Clark T., Ameratunga S., et al. (2011). Sexual attraction, depression, self-harm, suicidality and help-seeking behaviour in New Zealand secondary school students. Australian and New Zealand Journal of Psychiatry, 45(5), 376-383. doi: 10.3109/00048674.2011.559635 http://dx.doi.org/10.3109/00048674.2011.559635

Marshal, M. P., Dietz, L. J., Friedman, M. S., Stall, R., Smith, H. A., McGinley, J., et al. (2011). Suicidality and depression disparities between sexual minority and heterosexual youth: A metaanalytic review. Journal of Adolescent Health, 49(2), 115-123.

doi: 10.1016/j.jadohealth.2011.02.005 http://dx.doi.org/10.1016/j.jadohealth.2011.02.005 
International Journal of Child, Youth and Family Studies (2014) 1: 89-112

McGuffey C.S., \& Rich, B. L. (1999). Playing in the gender transgression zone: Race, class, and hegemonic masculinity in middle childhood. Gender \& Society, 13(5), 608-627. http://dx.doi.org/10.1177/089124399013005003

North Vancouver School District No. 44 v. Jubran, BCJ No. 733, BCCA 201 (2005).

Ott, M. Q., Corliss, H. L., Wypij, D., Rosario, M., \& Austin, S. B. (2011). Stability and change in selfreported sexual orientation identity in young people: Application of mobility metrics. Archives of Sexual Behavior, 40(3), 519-532. http://dx.doi.org/10.1007/s10508-010-9691-3

Poon, C., \& Saewyc, E. (2009). “Out” yonder: Sexual minority youth in rural and small town areas of British Columbia. American Journal of Public Health, 99(1), 118-124. PMC2636614. http://dx.doi.org/10.2105/ajph.2007.122945

Poteat, V. P., Sinclair, K. O., DiGiovanni, C. D., Koenig, B. W., \& Russell, S. T. (2012). Gay-straight alliances are associated with school health: A multi-school comparison of LGBTQ and heterosexual youth. Journal of Research on Adolescence, 23(2), 319-330. doi: 10.1111/j.15327795.2012.00832.x. http://dx.doi.org/10.1111/j.1532-7795.2012.00832.x

Rivers, I. (2001). The bullying of sexual minorities at school: Its nature and long-term correlates. Educational \& Child Psychology, 18, 33-46.

Rose, H. A. (2009). A contextual model of victimization of sexual minority youth. In L. Chamberland, B. W. Frank, \& J. Ristock (Eds.), Diversité sexuelles et constructions de genre (pp. 75-101). Québec, QC: Presses de l'Université du Québec.

Russell, S. T. (2005). Beyond risk: Resilience in the lives of sexual-minority youth. Journal of Lesbian and Gay Issues in Education, 2, 5-17. http://dx.doi.org/10.1300/j367v02n03_02

Russell, S. T., Muraco, A., Subramaniam, A., \& Laub, C. (2009). Youth empowerment and high school gay-straight alliances. Journal of Youth and Adolescence, 38(7), 891-903. http://dx.doi.org/10.1007/s10964-008-9382-8

Saweyc, E. M. (2007). Contested conclusions: What claims can (and cannot) be made from the current research on gay, lesbian, and bisexual teen suicide attempts? Journal of LGBT Health Research, 3(1), 79-87. http://dx.doi.org/10.1300/j463v03n01_09

Saewyc, E. M. (2011). Research on adolescent sexual orientation: Development, health disparities, stigma, and resilience. Journal of Research on Adolescence, 21(1), 256-272. http://dx.doi.org/10.1111/j.1532-7795.2010.00727.x

Saewyc, E. M., Bauer, G. R., Skay, C. L., Bearinger, L. H., Resnick, M. D., Reis, E., et al. (2004). Measuring sexual orientation in adolescent health surveys: Evaluation of eight school-based surveys. Journal of Adolescent Health, 35(4), 345e.1-e.16, on-line at http://download.journals.elsevierhealth.com/pdfs/journals/1054139X/PIIS1054139X04001612.pdf. 
International Journal of Child, Youth and Family Studies (2014) 1: 89-112

Saewyc, E. M., Bearinger, L. H., Heinz, P. A., Blum, R. W., \& Resnick, M. D. (1998). Gender differences in health and risk behaviors among bisexual and homosexual adolescents. Journal of Adolescent Health, 23(2), 181-188. http://dx.doi.org/10.1016/s1054-139x(97)87565-9

Saewyc, E. M., Bearinger, L. H., Blum, R. W., \& Resnick, M. D. (1999). Sexual intercourse, abuse, and pregnancy among adolescent women: Does sexual orientation make a difference? Family Planning Perspectives, 31(3), 127-131. http:/dx.doi.org/10.2307/2991695

Saewyc, E. M., Poon, C., Homma, Y., \& Skay, C. L. (2008). Stigma management? The links between enacted stigma and teen pregnancy trends among gay, lesbian and bisexual students in British Columbia. Canadian Journal of Human Sexuality, 17(3), 123-131.

Saewyc, E. M., Poon, C., Wang, N., Homma, Y., Smith, A., \& McCreary Centre Society. (2007). Not yet equal: The health of lesbian, gay, \& bisexual youth in BC. Vancouver, BC: McCreary Centre Society.

Saewyc, E., Richens, K., Skay, C. L., Reis, E., Poon, C., \& Murphy, A. (2006). Sexual orientation, sexual abuse, and HIV-risk behaviors among adolescents in the Pacific Northwest. American Journal of Public Health, 96(6), 1104-1110. PMC1470640. http://dx.doi.org/10.2105/ajph.2005.065870

Saewyc, E. M., Skay, C. L., Hynds, P., Pettingell, S., Bearinger, L. H., Resnick, M. D., \& Reis, E. (2007). Suicidal ideation and attempts among adolescents in North American school-based surveys: Are bisexual youth at increasing risk? Journal of LGBT Health Research, 3(2), 25-36. PMC2765809. http://dx.doi.org/10.1300/j463v03n02_04

Saunders, J. M., \& Valente, S. M. (1987). Suicide risk among gay men and lesbians: A review. Death Studies, 11, 1-23. http://dx.doi.org/10.1080/07481188708252171

Savin-Williams, R. C. (2005). The new gay teenager. Boston: Harvard University Press.

Smyser, M., \& Reis, B. (2002, August). Bullying and bias-based harassmsent in King County schools. Public Health Data Watch 5(2), 1-16. Accessed from http://www.kingcounty.gov/healthservices/health/data/youth.aspx.

Suicide Prevention Resource Center. (2008). Suicide risk and prevention for lesbian, gay, bisexual, and transgender youth. Newton, MA: Education Development Center, Inc.

Swearer, S. M., Turner, R. K., Givens, J. E., \& Pollack, W. S. (2008). “You’re so gay!” Do different forms of bullying matter for adolescent males? School Psychology Review, 37(2), 160-173.

Szalacha, L. A. (2003). Safer sexual diversity climates: Lessons learned from an evaluation of Massachusetts Safe Schools Program for Gay and Lesbian Students. American Journal of Education, 110(1), 58-88. http://dx.doi.org/10.1086/377673 
International Journal of Child, Youth and Family Studies (2014) 1: 89-112

Taylor, C., Peter, T., McMinn, T. L., Elliott, T., Beldom, S., Ferry, A., et al. (2011). Every class in every school: The first national climate survey on homophobia, biphobia, and transphobia in Canadian schools. Final report. Toronto: Egale Canada Human Rights Trust.

Thompson, K. (1982). Emile Durkheim. New York: Ellis Horwood. http://dx.doi.org/10.4324/9780203405338

Toomey, R. B., McGuire, J. K., \& Russell, S. T. (2012). Heteronormativity, school climates, and perceived safety for gender nonconforming peers. Journal of Adolescence, 35(1), 187-196. http://dx.doi.org/10.1016/j.adolescence.2011.03.001

Toomey, R. B., Ryan, C., Diaz, R. M., \& Russell, S. T. (2011). High school gay-straight alliances (GSAs) and young adult well-being: An examination of GSA presence, participation, and perceived effectiveness. Applied Developmental Science, 15(4), 175-185. http://dx.doi.org/10.1080/10888691.2011.607378

Tyler, K. (2008). A comparison of risk factors for sexual victimization among gay, lesbian, bisexual, and heterosexual homeless young adults. Retrieved from http://digitalcommons.unl.edu/sociologyfacpub/41 http://x.doi.org/10.1891/0886-6708.23.5.586

Wald, K. D., Rienzo, B. A., \& Button, J. W. (2002). Sexual orientation and education politics: Gay and lesbian representation in American schools. Journal of Homosexuality, 42(4), 145-168.

Waldo, C. R., Hesson-McInnis, M. S., \& D’Augelli, A. (1998). Antecedents and consequences of victimization of lesbian, gay and bisexual young people: A structural model comparing rural university and urban samples. American Journal of Community Psychology, 26(2), 307-334.

Walls, N. E., Freedenthal, S., \& Wisneski, H. (2008). Suicidal ideation and attempts among sexualminority youth receiving social services. Social Work, 53(1), 21-29. http://dx.doi.org/10.1093/sw/53.1.21

Walls, N. E., Kane, S. B., \& Wisneski, H. (2010). Gay-straight alliances and school experiences of sexual-minority youth. Youth \& Society, 41(3), 307-332. http://dx.doi.org/10.1177/0044118x09334957

Wichstrom, L., \& Hegna, K. (2003). Sexual orientation and suicide attempt: A longitudinal study of the general Norwegian adolescent population. Journal of Abnormal Psychology, 112(1), 144-151. http://dx.doi.org/10.1037/0021-843x.112.1.144

Woodford, M. R., Howell, M. L., Silverschanz, P., \& Yu, L. (2012). “That’s so gay!”: Examining the covariates of hearing this expression among gay, lesbian, and bisexual college students. Journal of American College Health, 60(6), 429-434. http://dx.doi.org/10.1080/07448481.2012.673519 